\title{
MAKING SENSE OF DOING WRONG: ON THE JUSTIFICATION OF COMPROMISE DECISIONS
}

\author{
Rafael Cejudo Córdoba \\ Facultad de Filosofía y Letras \\ Universidad de Córdoba (España) \\ rafael.cejudo@uco.es
}

SUMMARY: This paper holds that compromises are a kind of agreement and also a kind of decision. The main objectives are: 1) to identify the formal structure of compromise situations, or predicaments where some compromise decision (CD) is unavoidable, including CDs that jeopardize the decision-maker's integrity; 2) through Amartya Sen's notions of basic and compulsive judgments, to establish when a CD in a situation of compromise could be morally justified. It concludes that justified CDs involve a rationally justified moral regret which helps to bridge the gap between deontology and consequentialism.

KEY WORDS: moral judgment, dilemma, integrity, consequentialism, deontology

RESUMEN: El artículo defiende que los compromisos son tanto un tipo de acuerdo como un tipo de decisión. Los principales objetivos son: 1) identificar la estructura formal de las situaciones de compromiso en las que alguna decisión de compromiso (CD) es inevitable, incluyendo CDs que ponen en riesgo la integridad del decisor; 2) mediante las nociones de juicio básico y compulsivo propuestas por Amartya Sen, establecer cuándo una CD en una situación de compromiso podría estar moralmente justificada. Se concluye que las CDs justificadas implican una contrición moral que ayuda a salvar la distancia entre deontología y consecuencialismo.

PALABRAS CLAVE: juicio moral, dilema, integridad, consecuencialismo, deontología

\section{Introduction with Some Examples}

Under General Franco's dictatorship, the Spanish Communist Party (PCE) struggled against the regime under cover inside the country and openly abroad. Setting aside the degree to which the PCE contributed to the final success of the democratic forces, its leaders actually relinquished some of their most cherished communist ideals in order to facilitate the advent of democracy in Spain (Preston 2001; Tusell 2007). In the end, Communist leaders managed to convince their grassroots membership, to accept a bourgeois democratic system. Indeed, not just the PCE but almost every party and social organization, each in its own way, had to forsake an essential part of its agenda and even some of its most treasured symbols and ideals. Hence the 1978 Spanish Constitution was the result of a compromise between very different political outlooks. Of course, political history is a story of amendments, partial solutions and compromises, not 
only in this particular case of transition to democracy. Let us recall one of the American Constitution compromises. In 1787, during the Philadelphia Convention, Northern and Southern States reached a compromise to include part of the slave population in the calculations for each state contribution to the federal budget, and its level of representation in the Federal Congress (Lynd 1966; Walton and Smith 2011). Anti-slavery States did not wish to include slave population of the Southern states in the congressional apportionment. Naturally, Southern States wished the opposite. On the other hand, these states were disinclined to take into account the slave population for the purpose of determining their contributions to the federal budget, while the Northern states regarded this as unfair. In the end, Northern and Southern states came up with a compromise under which 60 per cent of the slave population was taken into account; this was named the Three-Fifths Compromise.

Compromising is a pervasive phenomenon, and it is certainly a key question in democratic politics. In fact it is part and parcel of any sort of political activity, because compromising is required wherever there is both cooperation and competition. There is a rather large bibliography regarding compromise in politics, particularly concerning its role in democracy from a liberal point of view (Arnsperger and Picavet 2004; Bellamy 2002; Berlin 1998; Besson 2005; Day 1989; Ferrié and Dupret 2004; Galston 2005; Kagan 1989; Kekes 1993; Stocker 1990). There is also some research addressing compromise as a form of negotiation. Rational choice literature is quite useful here (Arnsperger and Picavet 2004; Aumann 1976; Chun and Thomson 1992; Hirschleifer 1995; Varoufakis 1991; Yu 1973). However, compromise is necessary in many other spheres of social and personal life, involving bread-and-butter issues, family or working life, often calling for far-reaching or painful decisions. But let us go back for a moment to the above-mentioned examples from the political realm. In both examples, the parties to the conflicts pursued political goals of broader scope than just their conflicting interests. The disagreement concerned antagonistic ideals and deep differences on values and beliefs. Therefore it was not only a question of raw interests, and it would be misguided to look upon these compromises as mere examples of bartering. In particular, Spanish politicians had to accept their second or their third best, and the Three-Fifths Compromise involved sacrificing high anti-slavery standards.

It should be noted that specific people are involved in any compromise. In other words, to settle a dispute and reach a compromise, someone has to discuss, negotiate and give way. Santiago Carrillo, 
then leader of the PCE, or Adolfo Suárez, the moderate right-wing leader at the time, had to sacrifice some of their previous beliefs and betray some of their former commitments. In other words, they made a compromise in order to obtain a reasonable political agreement for the future. Maybe they compromised their integrity, or felt they did so, for the sake of their country. One of the Three-Fifths Compromise negotiators was the Constitutional Convention member Rufus King, strongly opposed to slavery. Like many Americans in the late eighteenth and early nineteenth centuries, he considered it was better to compromise than to split his country, although this might require putting his moral and religious principles at risk. I shall focus on this aspect of the compromising problem, rather than the process of negotiation that is usually the forerunner to a compromise. Carrillo and King made some decisions in their respective processes. They had to take hard and painful choices so as to eventually arrive at a compromise. Perhaps the decisions they made involved injustice or even getting their hands dirty. In other words, they had to make compromise decisions. I shall come back to this question shortly.

This article is divided into four sections. The first deals with the notion of compromise. Now, in the ordinary use of the word two different basic meanings can be distinguished. According to dictionary definitions, a compromise is an agreement or settlement that is achieved by mutual concessions. However, leaving aside the reference to a kind of agreement, a compromise is also a concession to something that is less than what one desires. In this second meaning, compromises are states or outcomes that are accepted as solutions although they make room for damaging or even derogatory consequences. Therefore, I shall consider that a compromise agreement (CA) is different from a compromise decision (CD), because although a compromise is a kind of agreement it also implies a kind of decision that an individual agent has to take in a negotiation or whenever a clear-cut solution is not possible. Hence, in opposition to the more frequent approach on compromise as negotiation, I shall focus on compromise as decision, and I shall discuss such decisions through analysis of the normative judgments involved. Some CDs can be considered merely as strategic devices in a negotiation, but others involve serious moral problems for decision makers. This is why I distinguish between strategic and moral compromises, and I pay close attention to integrity-compromising decisions, to wit, $\mathrm{CDs}$ that jeopardize moral principles or cherished values.

My approach differs from the literature in that it focuses on those predicaments where some compromise is inevitable (this is what I 
call a compromise situation or CS), and not on the conditions or procedures to find or obtain a, say, "right" compromise solution. My concern is rather with the structural features of compromise situations. I will try to show that in those situations there is a certain loss of value because the decision maker voluntarily accepts postponement of something that is right or otherwise mandatory. Obviously, this is tied in with the problem of the right compromise solution, because not just any CD is justified in a CS despite the fact that any choice entails a loss of value. All the same, since in a CS some compromise is inescapable, it is necessary to establish that a CS exists in order to determine whether a moral agent needs to accept a compromise solution. I shall explain that CSs arise when different norms come into conflict, when complying with agreements, respecting previous commitments, or when faced with incommensurability of choice, dilemmatic situations or lack of information. These are all root causes of CDs.

In the third section I turn to the formal presuppositions of a CD. This issue is linked to a more substantial one: taking for granted that a certain decision should be a compromise, when does it become integrity compromising? To answer this question I shall use some notions suggested by Amartya Sen. The concept of basic judgment will be used to find out when a choice involves a net loss of value according to the compromiser. I hold that if no basic judgment is concerned, then a non integrity-compromising decision is possible in that specific CS. On the other hand, even if a basic judgment is concerned, a CD may be integrity compromising but justified provided that this basic judgment is not a compulsive judgment. In the concluding section, I suggest that normative judgments are not only action-guiding devices. If we look upon CDs in this more comprehensive manner, deep ethical oppositions of the deontology vs. consequentialism sort could be tackled by some reasonable compromise.

\section{Notion of Compromise}

The word compromise means basically two different things, though there is a link between them. First, a compromise is a kind of agreement, and as such is the result of a negotiation. In a compromise everybody loses (more or less) in order to get a collective gain. None of the parties to the deal fully meets its goals, but this is the price that they have to pay to reach an accord. That is why, paradoxically, getting a compromise means making everybody happy while giving 
them less than what they wanted. In a compromise every party eventually accepts a balance between its desires and its possibilities, and thus the agreement is struck by means of mutual concessions. This is the first sense of the word in the Merriam-Webster Dictionary. However, the compromise is not only the result of the negotiation (a kind of deal), but also entails a process to reach that deal. This means we might have an unsuccessful give and take which fails to reach a joint agreement in spite of mutual concessions. On the other hand a compromise could be imposed on the parties in the event of their not reaching any agreement (Margalit 2010, pp. 53-54). This is what Golding calls a third-party compromise, in opposition to a directly negotiated compromise. The third party is an arbitrator, and she can seek a compromise in three different ways: adjudication, conciliation and therapeutic integration (Golding 1979, p. 20).

It is important to highlight that the ideas of compromise and agreement can be considered separately. Since the origin of a compromise is not always a negotiated deal, it cannot be fully defined just in terms of its origin. Aside from this, a compromise is a "position" in a debate or negotiation - a position considered inferior but preferred to others (Weinstock 2013, p. 539) —; consequently it will become an outcome with specific features. To illustrate, according to the second meaning of "compromise" in the Merriam-Webster Dictionary, it is "a concession to something derogatory or prejudicial". Therefore, leaving aside whether it arises out of negotiation or arbitration, that concession is a compromise decision (CD) that somebody has to take in a debate or negotiation process. In other words, to conclude an agreement the parties have to take the corresponding decision. Actually, to make a CD just one agent is needed because an intrapersonal compromise (Lepora 2012) can take place without any social process of "give-and-take". For instance, someone can strike a balance between likes and interests, so she eventually decides to study nursing instead of philosophy. This is what I shall call a CD in opposition to a compromise agreement (CA). Both are compromises because there is some kind of balance involved, and because the result of that balance includes recognizing that acting is unavoidable, and that some costs have to be paid.

Hence, along with the external dimension of a compromise, namely that agreements, policies and even decisions are external events, there is also an internal dimension. This aspect concerns the intrapersonal balancing of opposing values and principles that eventually leads to the external compromise (Benjamin 1990; Carens 1979; 
Lepora 2012). For example, Benjamin suggests that an internal compromise "aims at resolving conflict among competing values, principles and desires within a single person" (Benjamin 1990, p. 20). Benjamin avers that the use of "internal" is metaphorical, because the decision maker cannot divide herself to achieve a compromise agreement. Leaving aside whether this is a suitable image, a $C D$ is not at all a metaphor. Actually, by this expedient I shall discuss choices of a particular kind. Note that the compromise agreement problem deals with how a negotiation process yields a range of choices. This is about the generation of a "choice menu", while the CD problem is about which choice to take. This might be a question of moral psychology, but we can also focus on how a CD can be justified. In this sense I shall be concerned about the judgments that an agent could use to state her CD. That is no longer a problem of moral psychology but of ethical theory.

Making a CD involves two conditions: making concessions (condition 1) to something harmful, wrong or derogatory (condition 2). Both (1) and (2) are needed. In order to decide for one solution, it is required to give up something that the agent appreciates. That is why the compromise is a concession: it is made up by forsaking something that the agent feels valuable and, perhaps, other people do too. In the case of CA also (1) and (2) are needed for a strict (Benjamin 1990, p. 7), or sanguine (Margalit 2010, p. 40) compromise. When only (1) remains, rigorously speaking there is no compromise any longer but a mere deal, because the parties to a deal have to accept (or pretend they do) some concessions to get an agreement. In this loose sense almost any arrangement is a compromise, as Benjamin says.

Now it might be that (2) is related with interim targets or with more important things that the agent can nonetheless afford to exchange. There is some consensus in the literature on this kind of division, including Richardson (2003, p. 147) distinction between bare vs. deep compromises, or May's (2005) between pragmatic vs. principled compromises. In a similar way, I propose a distinction between self-interest and other axiological goals. For instance, sometimes a party to a compromise renounces its legitimate concerns just to advance its goals, so that the compromiser feels her interests are better served by an agreement than by enforcing her rights. For instance, a customer can decide not to implement her right to claim compensation in order to get in return a quicker refund. In both cases the compromise is a way to achieve a greater benefit, but it neither involves any further moral loss nor puts moral integrity into risk. I shall refer to strategic compromises if compromising is just a 
means to attain ulterior goals with a pragmatic approach, irrespective of their being CA or CD. The rationale behind this sort of compromise is that it would be prudent to settle for the best available choice, since the absolute best is beyond reach. Here consequential evaluation, particularly through rational choice theory, is quite useful for assessing the alternative CAs and the subsequent CDs. Strategic agreements are part of the theory of negotiation, since they are a way to manage conflict (Gauthier 1986; Hirschleifer 1995; Menkel-Meadow 2006; Varoufakis 1991). Then again, strategic CDs are probably a little disturbing from a moral point of view, because their rationality and correctness are merely instrumental. A strategic compromiser has no moral merit, but neither is she to blame. After all, it is her own business if she decides that her interests are better served by $A$ than by $B$.

Nevertheless, strictly strategic CAs and CDs are probably few (Gutmann and Thompson 2012, p. 12; Richardson 2003, p. 146), even none if exclusive focus on interests presupposes ultimately a moral decision in favor of strategic concerns (Smith 1942, p. 3). Either way, agents quite often have to scale down their principles in order to strike a compromise. Quite frequently other valuable things, not only venal interests, should be sacrificed to reach a balance. In other words, precious things may have to be relinquished along the way in order to meet each other half way. Therefore, I shall say there is a moral compromise whenever several values, and not only interests, are involved. Put another way, a moral compromise is required when a moral evaluation of choices is needed. So in moral compromises, condition (2) - the fact that something harmful, wrong or derogatory is involved - has a moral meaning, however we understand the word moral. As a result, a CA is strategic if and only if no more than venal interests are involved, all the parties have shown their voluntary agreement publicly and the final outcome is undeniably fair (Kuty and Nachi 2004; Margalit 2010; Van Parijs 2011). Consequently, if a strategic CD is wrong, this is negative just for the fulfillment of the agent's goals, because after all she has not compromised herself in spite of suffering some quantifiable setback. By the way, this is another meaning of the word: compromise is also understood as a kind of betrayal (Benjamin 1990). A moral CD entails the possibility of compromising our principles and values or those of others. As a result a compromise can do harm to oneself or to others, a kind of duplicity that is morally blameworthy. To avoid misunderstandings I shall call this last sense integrity compromising. A sufficient condition for a CD to be morally acceptable is not 
to be integrity compromising at all. In so doing the CD does not bring about any blameworthy harm. But this is not a necessary condition (Benjamin 1990; Margalit 2010). Sometimes a CD could involve compromising others or oneself integrity, and even so it could still be considered tolerable or justified. I shall look again at this issue in sections four and five.

\section{Situations of Compromise}

When is a compromise sound or necessary? In a similar way to Hume's circumstances of justice, Benjamin calls circumstances of compromise "those conditions that provide both the motivation and the grounds for compromise solutions" (Benjamin 1990, p. 26). He includes, among others, uncertainty, moral complexity, and the need to maintain a collaborative relation. Other authors choose different conditions to cast light on the circumstances of compromise (Benditt 1979; Besson 2005; Carens 1979; Golding 1979; Kuflik 1979; May 2005). Perhaps Smith's formulation covers all of them by these two general though loose requirements: compromises should be both necessary and desirable (Smith 1942). All of these conditions provide different answers to the question of how justifying compromises, but they share the emphasis on the solution that would be possible by compromising. In other words, the circumstances of compromise are reasons to accept a compromise as a solution because this is the only possible way (or the least bad one) to achieve an agreement. Those circumstances recommend being flexible in difficult situations, because then compromising should be considered a sensible solution, and quite possibly the best one. If necessity forces us to compromise, that means this is the wiser solution. Yet in this way just prudential reasons, though in a broad sense, are taken into account.

I shall focus on a different side of the justification problem, and for this reason I shall use the expression compromise situation (CS) instead of circumstances of compromise. Aside from whether the compromise solution is the best one, or even if it is possible, accepting a compromise could be morally required in some situations. These are predicaments where any accord or decision is faulty, so that compromising is unavoidable. I shall focus my attention on the fact that some decision is needed in those situations, and not on the correctness of the possible decision. In other words, I am concerned about how to justify compromise decisions, not compromise solutions. Since the notion of circumstances of compromise was conceived bearing in mind some desired agreement, they provide a justification 
in terms of the solutions that the compromise makes possible. But this is not the only possible approach because, leaving aside whether the compromise is a real solution or not (Golding 1979), a moral $\mathrm{CD}$ might be considered justified because there is no other available option. As an illustration, Kuflik (1979) claims that a CA is morally acceptable if it arises from the recognition that the objectives are too ambitious, apart from whether they are fair or not. Therefore, in this case a compromise could be something less than fair, and still yet justified.

As stated above, the balance is among values of the same kind (interests) in the case of strategic compromises. That is not necessarily so regarding moral compromises. Here the justification problem can be posed in this way: taking for granted that compromising is morally right in this particular situation, what is the content of the compromise? The answer is this: in a CS what is compromised is what ought to be done, setting aside the fact that a compromise is actually needed. Consequently, there will be a loss of value because the agent voluntarily postpones something that is right, and this is a loss that requires some justification. For example the agent may have to balance two right choices of the same sort, like deciding which of two moral rules has to be observed (for example, saying the truth to a third party, or remaining loyal to the group you are committed to, for instance, the company you work for). Furthermore, agents may have to balance alternative choices $(A$ or not $A$ ), with respect to one single moral scale like the Principle of Utility (as when fiscal authorities have to decide on a fiscal amnesty bearing in mind that the measure might improve tax revenues in spite of a possible disutility as a result of decreasing tax awareness). Additionally, the agent may have to arrive at a CD at situations where a common moral metric lacks, so that a moral compromise is produced, not merely by conflicting values, but also by the opposition of values and disvalues. This is the case when the agent compromises because she does not observe her duties (a moral wrong) in order to obtain a larger moral good, a kind of compromise between deontological and consequential reasons that is quite frequent (referring back to the previous example, a fiscal amnesty could be considered as a compromise between fiscal fairness and increasing efficiency in tax collection).

In summary, a CS is a predicament that precludes any choice other than a $\mathrm{CD}$, and a $\mathrm{CD}$ involves making concessions to something harmful, wrong or derogatory. Consequently, in a CS the agent recognizes that she has to admit some loss of value, particularly of moral value. In case of a strategic CD the agent accepts giving up 
her high-ranked options, but she does so in order to arrive at an advantageous balance. Therefore there is only apparently a loss of value. Indeed, there is an "intimate relation" between compromising and second best decisions, as Margalit (2010, p. 117) says. However let us note that "second best" might be a misleading expression here, because it does not mean that the agent could have made a better decision in terms of her personal benefit. That is to say it might be worse in comparison to an ideal situation, but actually the agent compromises because this is the optimizing strategy in this particular case. To return to the subject, a strategic CD does not merely involve forsaking our interests, but those interests that we are entitled to (Van Parijs 2011). Nevertheless, there is no moral wrong when we voluntarily renounce some right. As noted earlier, we may give up some non-economic right in order to obtain more money, but we do it voluntarily in order to better serve our interests. To demonstrate, let us consider the $\mathrm{CD}$ of not taking legal action for defamation in order to receive a prompt economic compensation through an informal settlement. Considering that the compromiser should be blamed for that would be paternalistic. To resume the subject of justification, the picture changes if the compromiser does not honor some of her duties. In a case like that there will be some loss of value. Nevertheless the compromise is justified if the decision-maker is in a CS. In other words, if the agent knows that she faces a CS, then she knows that some CD will be justified (though not which one). Consequently, that a CS exists is a way to ascertain when compromising is reasonable. Now, the problem is how to be sure that some real loss of moral value is unavoidable.

Beyond doubt that question depends on the specific circumstances of each case, and I do not aspire to establish any heuristic method for identifying CSs. However, I hold that a CS has special structural features, and that to be aware of those features is useful in order to be sure a compromise is needed. Let us recall once more that a compromise may be a concession to something derogatory or prejudicial. As I stated, a moral CD involves a concession to something wrong, and that means at least some loss of value. The agent forsakes the prima facie best choice, and she does so voluntarily though reluctantly. There might be several reasons for that: observing norms, complying with agreements, respecting previous commitments, incommensurability of choices and lack of information. The significance of my point is that those motives are not merely the causes of the CS, but of compromising in general. First I shall address CSs raised by conflicting norms. Let us imagine that the agent can choose between $A$ and $B$, 
and that $A$ is better than $B$, even morally better. I mean that $A$ better serves the agent's general morality, or that $A$ helps more than $B$ as to life fulfillment, and not just that $A$ is more interesting strategically. On the other hand, there is a rule $R$ that the agent ought to observe for whatever reason, so that $R$ prevents the agent from choosing $A$. The agent makes a CD if she chooses $A$, because it means not observing $R$, and in so doing the compromiser accepts some loss of value within her behavior. If the agent chooses $B$ and observing $R$, she compromises too, because she gives up a better choice in order to respect $R$. Is this a genuine loss of value, and so a moral compromise? On balance, there could eventually be no net loss of value because $B$ plus observing $R$ can be better that $A$ for prudential as well as other kind of reasons. Actually there are consequentalist approaches (Darwall 2003; Pettit 1993; Sen 1979, 1983, 2000) and deontological ones (Darwall 2006; Hampshire 2000; Weber 1919), that allow those kinds of trade-offs between norms and outcomes. Thus the apparent loss of value is due to narrow perspectives, for instance simplified forms or utilitarianism and Kantianism. In any case, if there were an ultimate loss of value in these cases, CDs would be integrity compromising although justified. I shall return to this in the final section.

A similar case is that of complying with agreements. As I said previously, a compromise can be discussed setting aside its origin (quite frequently an agreement). That is why I distinguished between compromise decision and compromise agreement (as mentioned, a deal that ends in a compromise). A fair pact, or a pact that the agent already is engaged in, is equivalent to a choice restriction. Let us consider again $A$ and $B$ as a choice menu. $A$ is better than $B$, even morally better, but the agent has agreed $B$. The agent deems that the agreement is fair or at least that she is bound by it, so she ought to comply with her part and that means she has to give up the more valuable $A$. If she does, she compromises (by definition). If she does not, she compromises too, in the sense that the agent makes a CD because she decides not to meet her side of the bargain so as to obtain the high-ranked $A$. Consequently the agent admits some loss of value (some wrongdoing). The compromiser has not fulfilled her part of the deal, and she is thus morally blameworthy (if the pact is a fair one), or at least she loses credibility. Nevertheless her CD could be sensible, all things considered. In fact this second case is quite similar to the former, because an agreement brings about some deontological obligation in the same way as a rule does (Nagel 1988). 
Another cause of a moral CD could be a previous engagement or a personal commitment. If the agent can personally bring about the preferred outcome, or if she has personal affiliations or family ties concerning the outcome, then there is a special relation between the agent and the state of affair that she appreciates (Parfit 1984). As an illustration, the agent gives up her best choice because she prefers to keep a secret or to fulfill a promise. In the same way, supporting our country or political party, feeding our children, keeping our social esteem or fulfilling a promise could be more important than obtaining some benefit. In all those cases the agent is committed to some goal that she considers truly valuable. Sen (1977) defines this kind of moral commitment as the election of sub-optimal choices compared to the possible welfare. If the agent is morally committed to some goal, she should seriously consider fostering that goal instead of improving her welfare. Put in a rather more formal way: if $A$ is better than $B$ in terms of welfare, but the agent is committed to $B$, then she should choose $B$ whenever her commitment definitely surpasses her welfare desires. Therefore, she would not make a moral CD at this occasion. Nevertheless, as McCabe (2010, p. 21) points out, due to commitment and integrity "an agent can often have decisive reasons, particular to his circumstances, to choose one option over another even when it is not intrinsically superior". Because in these cases $A$ is morally better than $B$ (putting aside the commitment to $B)$, the agent has to make some moral CD. In other words, the agent compromises whether she chooses $A$ or $B$ because she voluntarily accepts to lose something valuable in either case.

I shall turn now to the issues of incommensurability and lack of information (Chang 1997; Lariguet 2008; Williams 1981). In some of the instances that I discussed previously, there might be an opposition between (the value of) consequences and (the value of) rules. Rules, agreements or commitments are deontological restrictions that can clash against the value of outcomes otherwise paramount. Though in those cases a CD would be necessary, still this does not entail incommensurability between deontological and consequential criteria. Despite the fact that consequentialist and deontological claims can turn a deaf ear to each other, a lexical ranking of them could be set out within a more general theory of practical reason. For that ranking, a single and all-encompassing high-ranked value is not necessary. Specifically, if $A$ trumps $B$ (say $A$ is human rights and $B$ economic prospect), it does not mean that $A$ exceeds $B$ in some amount, it just means that $A$ is prior than $B$ in that particular situation. As Griffin 
(1986) points out, all that we need in order to avoid incommensurability is the possibility of pair-wise comparison, and that does not require a "common currency". On the contrary, all that is needed is a qualitative scale that yields a complete ordering.

An illustration of supposed incommensurability could be that of incompatible alternatives. As Lukes (1991) asserts, "incompatible moral claims become incommensurable when the trade-offs become unavailable because of there is no common currency". Leaving aside the need for a "common currency", is it indeed true that tradeoffs are not possible when incommensurability obtains? I claim that, rather, the opposite is the case. According to the Merriam-Webster Dictionary, a "trade-off" is a giving-up of one thing in return for another. This meaning suggests that items with identical value are exchanged. But "trade-off" also means "a balancing of factors all of which are not attainable at the same time". First of all, incompatibility and incommensurability should be distinguished, because $A$ and $B$ could be empirically or logically incompatible and still commensurable if they can be ranked. Second, incompatibility does not preclude a trade-off: if $A$ and $B$ are choices that the agent ought to choose, but she cannot accomplish both at the same time, a CD is the needed expedient. As it happens, incompatibility of beliefs weakens one (or all) of them, but incompatibility of desires (and especially of moral desires) does not, and this kind of incompatibility is the issue. Therefore, even if either of the aspirations could be justified, perhaps only one can be satisfied. Hence, in spite of choosing only one desire, the moral decision does not fully eliminate the other conflicting items (Williams 1976). Any of the choices raises some loss of value, and so any of the possible decisions is a compromise.

To return to the subject of real incommensurability, let us recall that this obtains where there is no scale for comparing two items even within a general theory of practical reason. But impossibility of pair-wise comparisons does not mean that an incommensurable alternative nullifies the value of the others. When we know that $A$ is valuable, that $B$ is too, and that they are non-rankable, we certainly lose if only one of the two can be chosen irrespective of the fact that every balance should be put aside. In this case, we can rank no one either quantitatively or qualitatively but still some decision is needed, and it has to be a compromise. Lack of information can yield a similar result. Let us assume that $A$ and $B$ are somewhat commensurable. However, if the required information for a pairwise comparison is lacking, the agent has to decide as if they were truly incommensurable. Larmore (1987) claims that in a predicament 
like that suspension of moral judgment could be right: until more information is available, it cannot be decided rationally whether the agent ought to choose $A$ or $B$. In spite of that, if some resolution cannot be delayed, then some compromise is required.

The question of availability of information is merged with that of dilemmas. Day (1991) discusses compromises in the context of moral dilemmas, and he claims that dilemmas are situations where the agent actually cannot adopt both alternatives though she ought to (Calabresi and Bobbitt 1978; Day 1989, 1991; Sinnott-Armstrong 1985; Ullmann-Margalit 2007). Others, like McNaughton (1988), assert that a dilemma is a situation where the person believes that she is simultaneously under several moral requirements, and thus she cannot honour all of them. The second view is enough for the analysis of CDs. Since perhaps new information could change her beliefs, the agent can discover that there is actually no incompatibility or incommensurability, and therefore no dilemma at all. Nevertheless, when some decision has to be made, a CS arises simply if the person takes himself to be under incommensurable choices. Sartre's famous dilemma of the young French student torn between staying with his mother or joining the resistance, provides an illustrative case (Sartre 2007). According to Sartre, the dilemma is so painful not as a result of the factual incompatibility of the two alternatives, but because the student was deeply convinced that the options were irreconcilable. I claim that at least some of those dilemmas could be solved by a compromise. It should be noted that I am not concerned with which compromise is the best solution of the dilemma. I just want to stress that some dilemmas are CSs (Sartre's for instance), and that not any CS is a dilemma. To illustrate the latter, if just one and only one clear-cut rule needs to be applied, then the agent will face a non-dilemmatic compromise if something valuable is lost as a result. As indicated above, this might be the case of fiscal authorities choosing between tax amnesty and fiscal awareness. Summing up, the CS lynchpin is the loss of value and not the potential impossibility of honouring all the duties or requirements involved. Consequently the so called ought-to-implies-can problem is not the same as that of the CS. Under certain circumstances a CD may be arrived at to tackle a dilemma, but other times it may be better to cut the Gordian knot, I mean not to compromise at all. Then again a compromise could be required even if there is no dilemma in sight. 


\section{Formal Pre-Conditions of a Compromise Decision}

In the previous section I focused on situations where a moral CD seems inescapable. Nevertheless the agent may still think that it is not worth compromising. If the agent does not compromise, then she will refuse to take part in an agreement, to perform her part of a common task, or to carry out some action. All these consequences of her refusal could be quite important, and it is an interesting question whether such results could rationally justify the lack of compromise or not. But I shall not pursue here that line of enquiry. Then again an agent in a CS could decide not to compromise out of cowardice, irrational prejudices or narrow-mindedness. Likewise the agent may deem that a compromise is not allowed within her moral standing. I shall discuss this last point: if the decision has to be a compromise, should it be integrity compromising? And, if the answer is in the affirmative, could the compromise be nevertheless justified? The answer depends on the specific features of each CS. Certainly, psychological and cultural questions are highly important (Benditt 1979; Benjamin 1990; Carens 1979; Margalit 2010), but I shall focus on the formal pre-conditions of a required CD. A decision is a psychological process, but it is also a choice from an option menu. Let us recall that a CD is a judgment used to state that choice. Therefore I shall discuss the formal relations between those judgments and other ones that also convey the agent moral standing in relation to some CS. My aim is not to infer some rules of compromising, or for assessing what is the best compromise for a particular CS. Instead, my goal is to determine in which way a CD could be coherent with the rest of the agent's moral view about the issue. I see this as a rather formal question, quite independent of the psychological and cultural elements involved in compromising. This analysis works toward including compromises in a theory of practical rationality, and casting light on the moral rightness of CDs. On the other hand, it is quite possible that my analysis does not conform accurately to any specific CD.

For this purpose I shall use some methods for classifying value judgments devised by Sen from the sixties onwards (Putnam 2002; Sen 1967). A value judgment is considered basic to a person "if no conceivable revision of factual assumptions can make him revise the judgment" (Sen 1967, p. 50). A value judgment is non-basic if such revisions could take place. In other words, if a judgment is non-basic, then the agent shall maintain that judgment only as long as certain circumstances obtain. If they do not, she will withdraw 
her support from that judgment. On the contrary, if the judgment is basic, the agent shall uphold under whatever circumstances. The majority of our value judgments are non-basic. For instance, someone may approve some political party as long as it is against nuclear energy. Since the judgment "the party $A$ is the best choice for the country" is then non-basic, the agent shall not sustain that judgment any longer if party A endorses nuclear energy.

Judgments are not essentially basic. The same judgment can be basic and non-basic to different people or to the same person at different moments. Sen writes that a judgment is basic to a person, though he does not explain why it is. I shall claim that basicness is to some extent a matter of each agent's choice. Indeed, in the case of some judgments it would be odd to allege their basicness under all circumstances (for instance maintaining that Chernobyl nuclear power plant was safe), and in others the agent should be blamed for her choice (for example judging that Hitler was an honest politician). However, basicness depends on the agent's will because it conveys her values; I mean that it communicates what is really important for her. If an agent claims that consuming marijuana is harmful, and this is a basic judgment to her, that judgment does not only show her opinion momentarily, but also her deep beliefs and her axiological commitments on the issue. Basicness requires that agents maintain the judgment under any factual revisions, not only under probable ones (Sen 1967, p. 51). If consuming marijuana is harmful is considered basic by someone, it means that she shall reject marijuana in any event; her assessment of the issue is thus entirely negative. Obviously, one may think that this is not reasonable since the agent is disregarding circumstances that could render consuming marijuana completely safe. Nevertheless, I am not concerned here about the existence of objective criteria for establishing the correctness of basic judgments.

A different issue is how the agent could be completely sure about what are her own basic judgments. Imagine a campaigner against nuclear energy who is convinced of its damaging effects. The judgment nuclear energy is bad for the environment seems basic to her. Hitherto the campaigner has not been able to find any reason to prefer nuclear energy, but it is possible to imagine new discoveries that make a completely safe nuclear power plant possible. This is a hypothetical circumstance that the campaigner had not still taken into account, and that can lead her to the discovery that she was wrong, and that her disapproval was thus not basic. Yet regarding some spheres of value, possibly the most important ones, it could be 
very difficult to imagine a revision of factual assumptions that would change a judgment into a non-basic one. Judgments like capital punishment is wrong or a good government is, at least, democratic seem basic to any person who agrees with them. It would be quite difficult for her to imagine any alternative factual circumstances that could provoke a change in her denunciation of capital punishment or her approval of democracy. To my view this is because those judgments show some of her deepest axiological commitments. According to her knowledge, past experiences, and general convictions, the agent decides that those judgments deserve to be basic, that they cannot be contradicted in any conceivable alternative scenario. If they were, that person would deem that something valuable is at risk. When basic judgments are not respected by others, or when personal behaviour is not in line with them, a serious loss of value arises from the agent's point of view.

Furthermore, basic judgments can be evidence of net losses of value, and not just of partial failures or lesser gains. Let us take the judgment no person with a criminal record is fit to be a Member of Parliament as basic (to some people). Imagine a post-terrorist scenario where former terrorists might become MPs. Since the judgment is basic, the prospect of an end to political violence does not constitute an adequate compensation for what is felt to be a grave transgression of values. Basicness means that there is no conceivable revision of factual assumptions that could justify a revision of the judgment, and obviously that includes the end of terrorism. For supporters of that judgment there is a net loss of value because, although no terrorism is actually an improvement, still it is not enough to compensate the moral error of permitting ex-terrorists to be parliamentarians. On the contrary, if the judgment were non-basic, a post-terrorist scenario could make revision of the judgment possible by making an exception, and so the balance between no terrorism and former terrorist MPs could be positive. In this case the agent could admit that there is some moral loss when compared to a Parliament without such members, but she deems that such a loss is ultimately worthwhile.

Accepting former terrorists in Parliament for the sake of peace can be a CD if the decision-maker believes that it is a concession to something wrong or derogatory. As I said previously, it is not my goal to discuss whether a specific CD like that would be the best solution ceteris paribus. My point is, rather, to ascertain if a CD is feasible within the value system of the agent, and thus non-integrity compromising. As the former terrorists instance shows, if no basic 
judgment is involved, then a non-integrity compromising decision is possible. The reason is this: if the judgment which marks the moral loss is non-basic, the CS may yield some of the factual assumptions that bring about its revision. The problem is more difficult if basic judgments are involved, because the agent will not reassess her judgments, however pressing the CS may be. Unfortunately, basic judgments are probably involved in some of the causes of a CS. Quite possibly, respect for norms like human rights, or for certain commitments to one's children are taken to be basic judgments. Likewise fulfilling our part in essential accords could entail a basic judgment. Nevertheless, through the predicament of a CS the agent might discover that some of her basic judgments actually ceased to be such. A prima facie basic judgment can eventually turn out to be non-basic, and this could be something that the agent realizes precisely when her judgment is at stake in a CS. Perhaps respecting certain human rights or complying with a peace agreement seemed basic only while the need for compromise was out of view.

Moreover there is a remarkable feature of basic judgments that helps in finding solutions to a C.S. Basic judgments do not always entail commandments, and so they do not always preclude making CDs. In such cases they still denote a net loss of value, but the agent is now free to compromise. According to Sen, this is because there are two ways in which value judgments can imply a commandment or a prohibition. First, a compulsive judgment conveys being in favour of $X$ against $Y$ in a way that implies the imperative "given that one and only one of X and Y must be chosen, let [me/you/Mr Q/everyone/all bald men/etc.] choose X" (Sen 1967, p. 48). Consequently, a compulsive judgment in favour of $X$ entails that if $X$ is in the choice menu, then the agent must decide $X$. It should be noted that if an agent only made compulsive judgments, no CD would be allowed her. Second, a value judgment which entails being in favour of $X$ against $Y$ is a non-compulsive judgment when "it implies an imperative in favour of $\mathrm{X}$ in a choice between the two, if one denies at the same time all conceivable value judgments giving a reason in favour of choosing Y against X" (Sen 1967, p. 48). To illustrate, note that $A$ $i$ nicer than $B$ is non-compulsive because it entails choosing $A$ only if there are no stronger reasons in favour of $B$. A CD presupposes this kind of value judgment: the compromiser deems that $A$ is morally more valuable, and thus she is in favour of $A$; at the same time, the compromiser holds that the reasons supporting the choice of $B$ could be stronger in this particular CS. It is interesting to note that a full compromiser will make only non-compulsive judgments. 
It is easy to think that a basic judgment has to be compulsive: because the assessment in favour of $A$ will not be modified in any factual circumstances, it seems that opting for $A$ is compulsory. However that is not always the case. In contrast to compulsiveness, basicness does not involve the idea of commandment. A non-compulsive judgment means that the agent sometimes assents to the judgment but not to its implicit commands (if there are any). Let us suppose that the judgments God is merciful and war is never a solution are basic. By hypothesis neither of the two is ever to be contradicted by factual circumstances. However the former does not recommend any precise course of action, so it is non-compulsive. Many basic judgments are of this kind. The latter can mean that if the alternatives are a longer/cruel/bigger war and a lesser one, then the lesser one must be chosen. Therefore if those kinds of judgments are put forward as basic, it does not necessarily mean that they must be interpreted as compulsive.

In a CS the agent could come to decide that some of her basic judgments can be taken as non-compulsive in order to facilitate a compromise. For instance the agent could believe that someone is entitled to a particular right in any case, but it does not mean that observing that right must always trump any other consideration. The agent may deem that, on this particular occasion, she is not under the obligation to observe the command involved in her value judgment. She approves the entitlement but with some exceptions (her judgment is non-compulsive). Now, those exceptions are about the commands involved in her value judgment, not about the fairness of the entitlement (because her judgment is basic). Consequently, there will be a loss of value if the right is eventually not respected in order to strike a compromise, and in this case the CD would be integrity compromising but justified within the agent's general outlook. Thus, clashes between basic judgments could be solved at the practical level of acceptable compromises which function as "incompletely theorized agreements" in such a way that people can agree on practices when they cannot agree on theories (Sunstein 2007, p. 1). Conflicts of human rights or "fundamental legal rights" (Zucca 2007) provide another good example because they lead to the kind of incommensurability of values that brings about a CS. It definitely will be so if each human right implies a basic judgment. In this CS the agent may deem that a solution is possible through compromising some of the rights. In spite of incommensurability, if the judgments involved are non-compulsive, a ranking of the corresponding commands will be possible. Therefore, due to non-compulsiveness the agent will deem 
that she is allowed to make a decision, and, due to basicness, that decision is integrity compromising. Indeed ranking the choices in order to decide does not mean that the compromiser disregards any of the conflicting human rights. As in other cases of conflict of values (Barragán 2008; De Wijze 2004; Stocker 1990; Williams 1976), a moral compromise involves some wrongdoing as a remainder within the act, and this circumstance should give raise to some moral regret in the decision-maker, a regret which is rationally justified.

\section{Conclusions}

By and large, compromises have a moral side because not only interests are taken into account to strike a balance. In principle, if the agent gains more than she loses, then a CD is rationally justified. However, in CSs deep moral conflicts are frequently involved. As a consequence those situations usually involve a net moral loss, and the compromiser loses not only in respect of a more favourable scenario, but in the sense of becoming blameworthy. Hence my contention that in a CS the agent is somehow compromised no matter what she eventually chooses. According to my definition, a CD need not be a "third way" out of a dilemma: each of the two horns could be a compromise, and we could eventually find a third alternative that would be a compromise too. That is why a loss of value, and not an "intermediate" result, defines a CD. The notion of compromise agreement requires a "third way", while that of compromise decision does not.

In a CS only CDs are possible, and this restriction should be taken into account in order to justify a compromise. However this is not sufficient, because an agent could refuse to compromise, and sometimes actually she ought to do so. While important, I have not touched on this issue in this paper. In any case, a CD is not integrity compromising if no basic judgment is entailed; nevertheless, an integrity compromising CD could also be justified within the agent's moral outlook. In fact, CD analysis could be part of a wider theory of non-optimal rational choice. According to the rational choice theory, rationality involves choice coherence as optimization through some binary relation of preference: if there is a choice between alternative actions, the right one is the best. The so-called second best theory still follows that line of thought, because a second best optimum would be the only one that it is attainable ceteris paribus (Lipsey and Lancaster 1956). Both versions of rational choice presuppose the consequentialist assumption of some betterness relation ( is better $^{2}$ than__) as the key to rational decision (Broome 1992). A moral CD 
does not respect that basic assumption. From a moral point of view, a CD is not a choice at least as good as any of the other alternatives, although it can be a rationally justified moral decision.

As a consequence, I believe that CDs loom larger when morality does not entirely deal with verdicts, sentences and acquittals. Moral problems are practical problems, and thus issues about what should be done in difficult situations (Hampshire 1989). CDs are quite often the sole expedient not only in spheres like politics or business, but also in many confused and messy daily life situations. Classifying judgments as basic/non-basic and compulsive/non-compulsive is useful to avoid an action-guiding orientation of value judgment that disapproves any less-than-optimal course of action. It should be noted that non-compulsiveness makes it possible for decision-makers to compromise avoiding contradictions among their choices. In this way an agent can eventually preserve her moral integrity, in spite of taking an integrity-compromising decision. On the other hand, as basicness means that a judgment is taken to be right a priori, compromising may entail a regret that is rationally justified regardless of how good the consequences of the CD are.

Stocker (1990, p. 183) points out that value judgments are usually made with a single "action-guiding orientation". It is frequently assumed that a value judgment is some command or advice for guiding personal action. According to this view, recognizing some value leads necessarily to encouragements, restrictions and prohibitions. Consequentialist theories maintain this approach because "consequentialism is the view that whatever values an individual or institutional agent adopts, the proper response to those values is to promote them" (Pettit 1993, p. 231). Likewise deontology endorses an actionguiding orientation, because deontology upholds that some actions are essentially right or wrong, and therefore they must be performed or avoided (Kant 1911; Ross 2002). Due to this action-guiding orientation, difficult conflicts and dilemmas arise when consequentialism and deontology do not agree. A CS may be an instance of the conflict between consequentialism and deontology. A compromise between both general outlooks might be possible by assuming away their action-guiding orientation. Therefore, it would be required to respect opposing values whilst a single course of action can be chosen. This would be a CD, that is to say a decision that honours both consequentialism and deontology but only partially. ${ }^{l}$

${ }^{1}$ I would like to thank two anonymous reviewers for Crítica. Preliminary versions of some of the ideas of this paper have been presented to audiences in the 


\section{REFERENCES}

Arnsperger, C. and E.B. Picavet, 2004, "More than Modus Vivendi, less than Overlapping Consensus: towards a Political Theory of Social Compromise", Social Science Information, vol. 43, no. 2, pp. 167-204.

Aumann, R., 1976, "Agreeing to Disagree", Annals of Statistics, vol. 4, no. 6, pp. 1236-1239.

Barragán, J., 2008, "La tragedia de decidir", in P. Francés, F. Lara, and M.A. Arráez (eds.), Ética en la práctica, Editorial Universidad de Granada, Granada, pp. 57-78.

Bellamy, R., 2002, Liberalism and Pluralism: Towards a Politics of Compromise, Taylor and Francis, New York.

Benditt, T.J., 1979, "Compromising Interests and Principles", in Pennock and Chapman 1979, pp. 26-37.

Benjamin, M., 1990, Splitting the Difference: Compromise and Integrity in Ethics and Politics, University Press of Kansas, Kansas.

Berlin, I., 1998, The Proper Study of Mankind: An Anthology of Essays, Pimlico, London.

Besson, S., 2005, The Morality of Conflict: Reasonable Disagreement and the Law, Hart Publishing, Oxford.

Broome, J., 1992, "Deontology and Economics", Economics and Philosophy, vol. 8, no. 2, pp. 269-282.

Calabresi, G. and P. Bobbitt, 1978, Tragic Choices, Norton and Company, New York.

Carens, J.H., 1979, "Compromise in Politics", in Pennock and Chapman 1979, pp. 123-142

Chang, R., 1997, Incommensurability, Incomparability, and Practical Reason, Harvard University Press, Cambridge, Mass.

Chun, Y.-s. and W. Thomson, 1992, "Bargaining Problems with Claims", Mathematical Social Science, vol. 24, no. 1, pp. 19-33.

Darwall, S. (ed.), 2006, Deontology, Blackwell, Oxford. (ed.), 2003, Consequentialism, Blackwell, Oxford.

Day, J.P., 1989, "Compromise", Philosophy, vol. 64, no. 250, pp. 471-485. 1991, "Moral Dilemmas, Compromise and Compensation", Philosophy, vol. 66, no. 257, pp. 369-375.

De Wijze, S., 2004, "Tragic-Remorse. The Anguish of Dirty Hands", Ethical Theory and Moral Practice, vol. 7, no. 5, pp. 453-471.

Ferrié, J.-N. and B. Dupret, 2004, "Préférences et pertinences: Analyse praxéologique des figures du compromis en contexte parlementaire. À propos d'un débat Égyptien", Social Science Information, vol. 43, no. 2, pp. 263-290.

Universities of Granada, Málaga and Córdoba. Thanks are also due to audiences in those venues for discussion and criticism. I am likewise particularly grateful to Lilian Bermejo, Stephen De Wijze, Pedro Francés, Javier Rodríguez and José María Rosales. 
Galston, W.A., 2005, The Practice of Liberal Pluralism, Cambridge University Press, Cambridge.

Gauthier, D., 1986, Morals by Agreement, Oxford University Press, Oxford.

Golding, M.P., 1979, "The Nature of Compromise: A Preliminary Inquiry", in Pennock and Chapman 1979, pp. 3-25.

Griffin, J., 1986, Well-Being. Its Meaning, Measurement and Moral Importance, Clarendon Press, Oxford.

Gutmann, A. and D. Thompson, 2012, The Spirit of Compromise, Princeton University Press, Princeton.

Hampshire, S., 2000, Justice Is Conflict, Princenton University Press, Princenton. London.

Hirschleifer, J., 1995, "Theorizing about Conflict", in K. Hartley and T. Sandler (eds.), Handbook of Defence Economics, North Holland, Amsterdam, pp. 165-189.

Kagan, S., 1989, The Limits of Morality, Oxford University Press, Oxford.

Kant, I., 1911, Grundlegung zur Metaphysik der Sitten, Walter de Grunter, Berlin.

Kekes, J., 1993, The Morality of Pluralism, Princeton University Press, Princeton.

Kuflik, A., 1979, "Morality and Compromise", in Pennock and Chapman 1979, pp. 38-65.

Kuty, O. and M. Nachi, 2004, "Le compromis, rationalité et valeur: Esquisse d'une approche sociologique", Social Science Information, vol. 43, no. 2, pp. 307-330.

Lariguet, G., 2008, Dilemas y conflictos trágicos: una investigación conceptual, Palestra, Lima/Bogotá.

Larmore, C., 1987, Patterns of Moral Complexity, Cambridge University Press, Cambridge.

Lepora, C., 2012, "On Compromise and Being Compromised", Journal of Political Philosophy, vol. 20, no. 1, pp. 1-22.

Lipsey, R.G. and K.J. Lancaster, 1956, "The General Theory of Second Best", The Review of Economic Studies, vol. 24, no. 1, pp. 11-32.

Lukes, S., 1991, Moral Conflict and Politics, Clarendon Press, Oxford.

Lynd, S., 1966, "The Compromise of 1787", Political Science Quarterly, vol. 81, no. 2 , pp. 225-250.

Margalit, A., 2010, On Compromise and Rotten Compromises, Princeton University Press, Princeton.

May, S.C., 2005, "Principled Compromise and the Abortion Controversy", Philosophy and Public Affairs, vol. 33, no. 4, pp. 317-348.

McCabe, D., 2010, Modus Vivendi Liberalism, Cambridge University Press, Cambridge.

McNaughton, D., 1988, Moral Vision: An Introduction to Ethics, Blackwell, Oxford. 
Menkel-Meadow, C., 2006, "The Ethics of Compromise", in A.K. Schneider and C. Honeyman (eds.), The Negotiator's Fieldbook, American Bar Association, Washington, pp. 155-164.

Nagel, T., 1988, "Autonomy and Deontology", in S. Scheffler (ed.), Consequentialism and Its Critics, Oxford University Press, New York, pp. 142-173.

Parfit, D., 1984, Reasons and Persons, Clarendon Press, Oxford.

Pennock J. and B. Chapman (eds.), 1979, Compromise in Ethics, Law and Politics, New York University Press, New York.

Pettit, P. (ed.), 1993, Consequentialism, Dartmouth, Aldershot.

Preston, P., 2001, The Triumph of Democracy in Spain, Routledge, London.

Putnam, H., 2002, The Collapse of the Fact/Value Dichotomy and Other Essays, Harvard University Press, Cambridge, Mass.

Richardson, H.S., 2003, Democratic Autonomy: Public Reasoning about the Ends of Policy, Oxford University Press, Oxford.

Ross, W.D., 2002, The Right and the Good, Oxford University Press, Oxford.

Sartre, J.P., 2007, Existentialism Is a Humanism, Yale University Press, New Haven.

Sen, A., 2000, "Consequential Evaluation and Practical Reason", The Journal of Philosophy, vol. 97, no. 9, pp. 477-502.

_- 1983, "Evaluator Relativity and Consequential Evaluation", Philosophy and Public Affairs, vol. 12, no. 2, pp. 113-132.

- 1979, "Utilitarianism and Welfarism", The Journal of Philosophy, vol. 76, no. 9, pp. 463-489.

— 1977, "Rational Fools: A Critique of the Behavioural Foundations of Economic Theory", Philosophy and Public Affairs, vol. 6, no. 4, pp. 317-344.

— 1967, "The Nature and Classes of Prescriptive Judgments", Philosophical Quarterly, vol. 17, no. 66, pp. 46-62.

Sinnott-Armstrong, W., 1985, "Moral Dilemmas and Incomparability", American Philosophical Quarterly, vol. 22, no. 4, pp. 321-329.

Smith, T.V., 1942, "Compromise: Its Context and Limits", Ethics, vol. 53, no. 1, pp. 1-13.

Stocker, M., 1990, Plural and conflicting values, Clarendon, Oxford.

Sunstein, C.R., 2007, "Incompletely Theorized Agreements in Constitutional Law", Social Research, vol. 74, no. 1, pp. 1-24.

Tusell, J., 2007, Spain: From Dictatorship to Democracy, 1939 to the Present, Blackwell, London.

Ullmann-Margalit, E., 2007, "Difficult Choices: To Agonize or Not to Agonize?", Social Research, vol. 74, no. 1, pp. 51-78.

Van Parijs, P., 2011, “Qu'est-ce qu'un bon compromis?", Raison publique, no. 14, pp. 229-243.

Varoufakis, Y., 1991, Rational Conflict, Blackwell, Oxford. 
Walton, H.J. and R.C. Smith, 2011, American Politics and the African American Quest for Universal Freedom, Longman, New York.

Weber, M., 1919, Politik als Beruf, Wissenschaft als Beruf, Duncker und Humboldt, Munich.

Weinstock, D., 2013, "On the Possibility of Principled Moral Compromise", Critical Review of International Social and Political Philosophy, vol. 16, no. 4, pp. 537-556.

Williams, B., 1981, Moral Luck: Philosophical Papers, 1973-1980, Cambridge University Press, Cambridge.

—_, 1976, Problems of the Self: Philosophical Papers 1956-1972, Cambridge University Press, Cambridge.

Yu, P.L., 1973, "A Class of Solutions for Group Decision Problems", Management Science, vol. 19, no. 8, pp. 936-946.

Zucca, L., 2007, Constitutional Dilemmas: conflicts of Fundamental Legal Rights in Europe and the USA, Oxford University Press, Oxford.

Received: February 13, 2013; revised: September 30, 2013; accepted: October 1, 2013. 